Article

\title{
In-Situ Synthesis and Characterization of Biodegradable Estolides via Epoxidation from Canola Biodiesel
}

\author{
Venu Babu Borugadda $@$ and Ajay K. Dalai * \\ Catalysis and Chemical Reaction Engineering Laboratories, Department of Chemical and Biological Engineering, \\ University of Saskatchewan, Saskatoon, SK S7N 5A9, Canada; vbb123@mail.usask.ca \\ * Correspondence: ajay.dalai@usask.ca; Tel.: +1-306-966-4771; Fax: +1-306-966-4777
}

Received: 1 August 2018; Accepted: 23 October 2018; Published: 25 October 2018

\begin{abstract}
Research on the formulation of estolides from plant seed oils has attracted substantial attention due to their favorable low-temperature properties and environmentally friendly nature. The present research investigates the formulation of canola biodiesel derived estolides for low-temperature applications. The dual-step research method includes ring opening of epoxidized canola biodiesel in the presence of oleic acid, followed by esterification with oleic acid to produce estolides using a mesoporous aluminosilicates possessing Modernite Framework Inverted (MFI) type pentasil structure as a heterogeneous acidic catalyst. Prepared catalyst was characterized to measure the properties essential for the effective catalysis. The catalyst demonstrated promising activity for the estolides formation, $>95 \%$ conversion was achieved at $110{ }^{\circ} \mathrm{C}$ for $6 \mathrm{~h}$ using $15 \mathrm{wt} \%$ of catalyst loading. ${ }^{1} \mathrm{H}$ NMR technique and oxirane oxygen titrimetric analysis were employed to determine product purity. Physicochemical properties of the reaction products were determined by standard methods and characterization results revealed that the formulated estolides had improved low-temperature, lubricity and rheological properties, and thermo-oxidative stability. Also, biodegradability of the estolides was found to be $92 \%$ within 28 days as per the bio-kinetic model. Wear scar diameter of $106 \mu \mathrm{m}$ was noticed for $10 \%$ of alkoxide blend with standard diesel fuel. Overall, outcomes of the physicochemical characterization data indicated that the prepared estolides can act as possible alternative bio-lubricant basestock for various low-temperature applications.
\end{abstract}

Keywords: alumino silicates; biodegradability; biolubricants; canola biodiesel; epoxides; estolides

\section{Introduction}

In pursuit of environmentally friendly products and processes, vegetable oils and their derivatives are beginning to economically supplant fossil fuel derivatives in the market. Modifying the structure of the vegetable oils is one of the most beneficial techniques to convert them into value-added products. Among the various structural modifications (hydrolysis, alcoholysis, epoxidation, hydrogenation, and oligomerization), epoxidation is one of the preeminent techniques to modify the chemical structure of mono- and polyunsaturated fatty acids present in plant seed oils [1]. Epoxidation of vegetable oils makes numerous value-added chemicals, fuels and lubricant basestocks such as hydroxyl derivatives, alkoxides, estolides, and esterified products. There have been several studies reported on the preparation of epoxides, hydroxyl derivatives and alkoxides from different sources of vegetable oils along with thorough physicochemical characterization of the end products [2,3]. Findings from those studies reported that low-temperature performance is still limited to those derivatives. However, owing to excellent low-temperature properties and thermo-oxidative stability associated with vegetable oil based derivatives, estolides are gaining much attention. 
Estolides are natural/synthetic chemical compounds derived from the fatty acid components of vegetable oils. The estolide structure is formed by the oligomerization or branching of different fatty acids via ester linkage of one fatty acid molecule to the alkyl backbone of another fatty acid. A number of fatty acid linkages are used to formulate the estolide, which is known as estolide number (EN). The estolide number is defined as the average number of fatty acids added to a base fatty acid molecule [4]. The ester linkage of the estolides are more resistant to hydrolysis than triacylglycerol and the unique chemical structure of these estolides leads to materials that have far superior performance in their physical properties such as poor thermo-oxidative stability, low hydrolytic stability and inadequate cold flow properties for certain applications than vegetable and fossil fuel derived oils $[4,5]$. Therefore, estolides and their esters have been known for over a decade and presently research continues to reach a better understanding of the structural functions of estolides.

To date, different kinds of estolides and their esters have been developed and tested. A comprehensive review of the investigations on the formulation of various kinds of estolides and their property evaluation by Cermak and Isabell $[4,5]$ is given in Supplementary Materials (Section S1). Most of their work focused on estolides formulation from ricinoleic acid with different saturated fatty acids, mono-unsaturated fatty acids and small, long chain alcohols using perchloric acid as a catalyst. However, there are few reports available on estolides formation via epoxidation route. Kiatsimkul et al. [6] reported on the preparation of ricinoleic acid estolides using lipase as a catalyst at $170{ }^{\circ} \mathrm{C}$ for $120 \mathrm{~h}$ of reaction time with oleic acid $(0.66 \mathrm{~mol})$ to produce high equivalent weight vegetable oil-based polyol from epoxidized soybean oil. Ashby et al. [7] derived unsaturated estolide ester from the sophorolipids made from the bioconversion of a mixture of glucose (GLC) to linoleic acid (LA) and an epoxy estolide ester to oleic acid (OA) substrates to use them as additives in solution-cast poly (3-hydroxybutyrate) (P3HB) films.

Doll et al. [8] converted unsaturated sites in oleic 2-Ethylhexyl estolide esters into epoxide and five-membered cyclic carbonate groups with supercritical carbon dioxide in the presence of tetrabutylammonium bromide catalyst. Cyclic carbonate products were confirmed by Fourier Transform Infrared Spectroscopy (FTIR) and ${ }^{13} \mathrm{C}$-Nuclear Magnetic Resonance (NMR) spectra and dynamic viscosity of the cyclic carbonated estolides was found to be $172 \mathrm{mPa}$.s at $25{ }^{\circ} \mathrm{C}$. Later on, Doll et al. [9] explored on the epoxidation and carbonation of castor oil based estolides and synthesis of cyclic carbonate esters. Former studies by Cermak and Isabell, Kiatsimkul et al., and Doll et al. [4-6,9] reported that, perchloric acid, lipase, tetrabutylammonium bromide were used as a commercial catalysts for estolides preparation. In the present study, mesoporous aluminosilicates were prepared and reported for the first time to formulate estolides through epoxidation. In addition to the above-cited literature, there was no detailed study on the preparation of estolides via epoxidation route using mesoporous aluminosilicates and their detailed characterization to find a suitable area of application. The main objective of this study is to formulate estolides with viable synthesis route from canola biodiesel via epoxidation, oxirane ring opening followed by esterification with oleic acid in the presence of mesoporous aluminosilicates as a heterogeneous acidic catalyst, evaluating the performance (pour point, biodegradability, rheological and lubricity properties) of the formulated estolides. Also, as per our knowledge, this could be the first study that investigates the estolides formulation from canola biodiesel via epoxidation route using mesoporous aluminosilicates.

\section{Experimental}

\subsection{Materials}

Canola biodiesel was obtained from Milligan Biofuels Inc. (Foam Lake, SK, Canada), epoxidized canola biodiesel was prepared as per the method described by Borugadda et al. [10]. Oleic acid and reagents for the catalyst preparation and characterization were purchased from Sigma-Aldrich (St. Louis, MO, USA); all the reagents were used without any further purification. 


\subsection{Analytical Techniques and Methods}

Physicochemical properties of the formulated estolides were determined according to the applicable standard methods. The biodegradation profile of the estolides was anticipated using Bio-kinetic model as per ASTM D7373-12 method based on the effective composition to biodegradation i.e., component of estolides that can be biodegradable by bacteria The effective composition to biodegradation was carried out by eluting the estolides with n-pentene (for nonaromatics), toluene and n-pentene (for nonpolar aromatics), diethyl ether (for ester fraction), chloroform and ethyl alcohol (for polar-aromatics) in a glass chromatographic column packed with silica gel. The solvents were completely removed by evaporation and the residues were calculated as the non-aromatics, non-polar aromatics, ester fractions and polar aromatics of the estolides. The effective composition to biodegradation was calculated by the following formula (1).

$$
\mathrm{ECB}=\sum_{\mathrm{a}}^{\mathrm{c}}(\eta \mathrm{aCa}+\eta \mathrm{cCc})
$$

where:

$\eta=$ effective composition to biodegradation coefficient ( 1 for natural esters and 0.8 for renewable based diester and polyol ester)

$C_{\mathrm{a}}=$ Fraction of non-aromatics (n-pentene)

$C_{c}=$ Fraction of ester (diethyl ether)

The biodegradability of the estolides was calculated by the following formula (2).

$$
B(t)=B(1)+\frac{0.49}{\ln \left(6.8 \times E C B^{-2.38}\right)} \ln t
$$

where:

$t=$ time (i.e., 28 days)

$\mathrm{B}(t)=$ Biodegradability of estolides in 28 days

$\mathrm{B}(1)=0.01$

${ }^{1} \mathrm{H}$ NMR spectra were collected on a Bruker Avance $500 \mathrm{MHz}$ spectrometer (Bruker, Billerica, MA, USA) with a $5 \mathrm{~mm}$ Broadband Inverse (BBI) probe for product confirmation and formation of the estolides. The ${ }^{1} \mathrm{H}$ NMR spectra were referenced to $\delta 7.26 \mathrm{ppm}$ in a $\mathrm{CDCl}_{3}$ solvent for all the experiments. The ${ }^{1} \mathrm{H}$ NMR technique was used to measure the percentage of epoxy groups converted into estolides based on the conventional integration method at the respective chemical shifts.

Low-temperature properties of the estolides were examined by pour point (PP) using differential scanning calorimetry (DSC). DSC experiments were performed on DSC instrument (PerkinElmer, Inc., CT, USA), with a computer-based controller. To measure the pour point, the estolides mass of approximately $10 \mathrm{mg}$ was placed in the sample pan with a similar empty pan as a reference in the DSC module. During the measurement, the estolides was heated from ambient temperature to $50^{\circ} \mathrm{C}$ holding for $10 \mathrm{~min}$ under isothermal condition $\left(\right.$ at $50^{\circ} \mathrm{C}$ ), this helps in homogenizing and dissolving any waxy material present in the estolides. Then the system was cooled to $-30{ }^{\circ} \mathrm{C}$ at a steady rate of $5{ }^{\circ} \mathrm{C} / \mathrm{min}$ using a cryofill filled with liquid nitrogen as a cooling medium; further, it was heated from $-30{ }^{\circ} \mathrm{C}$ to $30{ }^{\circ} \mathrm{C}$ using same heating rate. The plots of heat flow $(\mathrm{mw})$ versus temperature $\left({ }^{\circ} \mathrm{C}\right)$ for each experiment was prepared, all the analyses were performed in duplicate and the average results are presented.

Rheological studies were carried out by rheometer (TA Instruments Rheometer, AR-G2 Model, TA Instruments, New Castle, Denver, USA), with 0.5 true gap using acrylic plate Solvent Trap (ST)-40 $\mathrm{mm}$ to overcome the slip effect. Shear stress versus shear rate measurements was recorded at varying shear rate from 10 to $1000 \mathrm{~s}^{-1}$ at diverse temperatures $\left(40,60,80\right.$ and $\left.100{ }^{\circ} \mathrm{C}\right)$ to examine the viscosity 
index (VI) and the relation between temperature versus viscosity. Therefore, flow behavior of the estolides can be investigated at different temperatures.

Lubricity was calculated by ASTM D6079-04 technique using a high-frequency reciprocating rig (HFRR) apparatus. Test samples were prepared by mixing of $1.96,1.9$, and $1.8 \mathrm{~mL}$ of standard diesel fuel with $0.04,0.1$, and $0.2 \mathrm{~mL}$ of prepared estolides and the test samples were placed in a test reservoir, which has a smooth metal surface of an HFRR. Before starting the experiment, a vibrator arm holding a nonrotating steel ball was loaded with $200 \mathrm{~g}$ of mass and is lowered until it contacts a test disk completely submerged in the test reservoir. The nonrotating steel ball was placed in contact with the metal surface to rub against the disk with a 1-mm stroke at a frequency of $50 \mathrm{~Hz}$ for $75 \mathrm{~min}$ at $25{ }^{\circ} \mathrm{C}$. After the analysis, the ball was removed from the vibrator arm and cleaned; and the wear scar diameter on the ball surface was measured using a microscope under $100 \times$ magnification using the following formula. The HFRR analysis was duplicated and the average results are reported in Section 3.3 with reproducibility data.

Wear Scar Diameter

$$
(\mathrm{WSD})=(\mathrm{M}+\mathrm{N}) / 2
$$

where: $\mathrm{M}=$ Major axis, $\mathrm{mm} ; \mathrm{N}=$ Minor axis, $\mathrm{mm}$.

\subsection{Catalyst Preparation}

A hydrothermal crystallization method was followed to synthesize the mesoporous aluminosilicates with $\mathrm{Si} / \mathrm{Al}$ ratio of 32 . In order to synthesize a catalyst, Tetraethyl orthosilicate (TEOS), Tetrapropylammonium hydroxide (TPAOH), water, Hexyltrimethylammonium bromide (HTAB), and Sodium Aluminate $\left(\mathrm{NaAlO}_{2}\right)$ were mixed well according to a molar ratio of 32 TEOS:1 $\mathrm{NaAlO}_{2}: 8$ TPAOH:13 HTAB: $1138 \mathrm{H}_{2} \mathrm{O}$. The blend of all the reagents was agitated at room temperature to acquire a clear solution and then transferred into PTFE (polytetrafluoroethylene) bottle for hydrothermal treatment in an oven at $170{ }^{\circ} \mathrm{C}$ for $48 \mathrm{~h}$ to allow crystallization under autogenous pressure. The resultant solid obtained after hydrothermal treatment was filtered and washed with distilled water. The white gel obtained after washing was then dried at $60^{\circ} \mathrm{C}$ for $12 \mathrm{~h}$, and then calcined in static air at $550{ }^{\circ} \mathrm{C}$ for $8 \mathrm{~h}$.

\subsection{Catalyst Characterization Methods}

Prepared mesoporous aluminosilicates were characterized by the following methods to determine and confirm the bulk and surface properties. The ammonia temperature programmed desorption ( $\mathrm{NH}_{3}$-TPD) behavior of aluminosilicates was recorded on TPD/TPR Quantachrome instruments (USA). Nearly $0.1 \mathrm{~g}$ of a catalyst sample was taken in a test vessel and purged with helium gas at $150{ }^{\circ} \mathrm{C}$ for $1 \mathrm{~h}$ to remove the adsorbed moisture and impurities. Ammonia gas ( $3 \mathrm{wt} \%$ of helium in $\mathrm{N}_{2}$ ) was then sent through the sample for $2 \mathrm{~h}$. The desorption of ammonia from the catalyst was studied between $100-650{ }^{\circ} \mathrm{C}$ at a ramp rate of $5^{\circ} \mathrm{C} / \mathrm{min}$. The textural properties such as pore diameter, desorption pore volume, and specific surface area were analyzed on a Micromeritics ASAP 2000 instrument with nitrogen adsorption-desorption isotherms, and operated at $77 \mathrm{~K}$. The Brunauer-Emmett-Teller (BET) method was used to determine the specific surface area, and pore size distributions were calculated according to Barrett-Joyner-Halenda (BJH) analysis. The thermal analysis of aluminosilicates was investigated on TGA-Q500 series (TA instruments). Approximately $8 \mathrm{mg}$ of catalyst sample was heated from 25 to $800{ }^{\circ} \mathrm{C}$ at $10{ }^{\circ} \mathrm{C} / \mathrm{min}$ heating rate to study the weight loss attributed to thermal degradation under a nitrogen atmosphere $(60 \mathrm{~mL} / \mathrm{min})$. Further, FTIR spectra were recorded on Bruker spectrophotometer (Vertex 70) between frequency range $4000-400 \mathrm{~cm}^{-1}$. The wide-angle powder $X$-ray diffraction (XRD) patterns of aluminosilicates were obtained with Bruker D8 diffractometer with a monochromatic $\mathrm{Cu} \mathrm{K} \alpha$ radiation source (wavelength $\lambda=0.154 \mathrm{~nm}$ ) to identify the crystallographic structure. The normal scan rate of $2^{\circ}$ scan per minute was used within the $2 \theta$ range of $10-90^{\circ}$ with a step size of 0.02. The X-ray photoelectron spectra (XPS, Kratos Analytical Inc., Wharfside, Manchester, UK) was recorded with Kratos AXIS Supra equipped with a 500-mm Rowland circle monochromated 
$\mathrm{Al} \mathrm{K} \alpha$ (hy $1486.7 \mathrm{eV}$ ) at the Saskatchewan Structural Sciences Center (University of Saskatchewan, SK, Canada). The survey scan spectra were collected in the $1200-0 \mathrm{eV}$ binding energy range in $1 \mathrm{eV}$ steps with a pass energy of $160 \mathrm{eV}$. The residual operating vacuum pressure was less than $2 \times 10^{-9}$ Torr during the data acquisition. The spectra were energy corrected using the adventitious carbon peak with a binding energy value of $284.8 \mathrm{eV}$. All peaks were deconvoluted and fitted with Computer aided surface analysis X-ray Photoelectron Spectroscopy (Casa XPS software, version 2.3.16 PR 1.6, Casa Software Ltd., Osaka, Japan).

\subsection{Estolides Synthesis Procedure}

A two-necked round bottom flask $(100 \mathrm{~mL})$ was used to prepare epoxidized canola biodiesel, synthesis procedure and the reactants ratio were adopted from Borugadda and Goud [2]. Epoxidized canola biodiesel oxirane ring opening studies were conducted using an experimental setup similar to the one reported by those researchers. The two-step research approach was employed in this study which includes; ring opening of epoxidized canola biodiesel in the presence of oleic acid, followed by esterification of hydroxyl groups with oleic acid to produce estolides (Scheme 1) in a single reaction using aluminosilicates as a heterogeneous acidic catalyst. Single parameter optimization technique was used to determine the exact optimum reaction time, temperature, catalyst loading, and molar ratio of reactant to oleic acid. Table 1 shows the process conditions varied to get the exact optimum reaction conditions. Estolides were formulated at 1:10 molar ratio of epoxide to oleic acid with $15 \mathrm{wt} \%$ of catalyst loading for $6 \mathrm{~h}$ of reaction time at $110{ }^{\circ} \mathrm{C}$ of reaction temperature. Formation of estolides was determined by ${ }^{1} \mathrm{H}$ NMR spectral technique and oxirane oxygen value using AOCS standard titration method (Cd 9-57) by withdrawing samples at regular time intervals. After the reaction, the catalyst was separated from the reaction mixture and detailed physicochemical characterization was carried out for estolides.
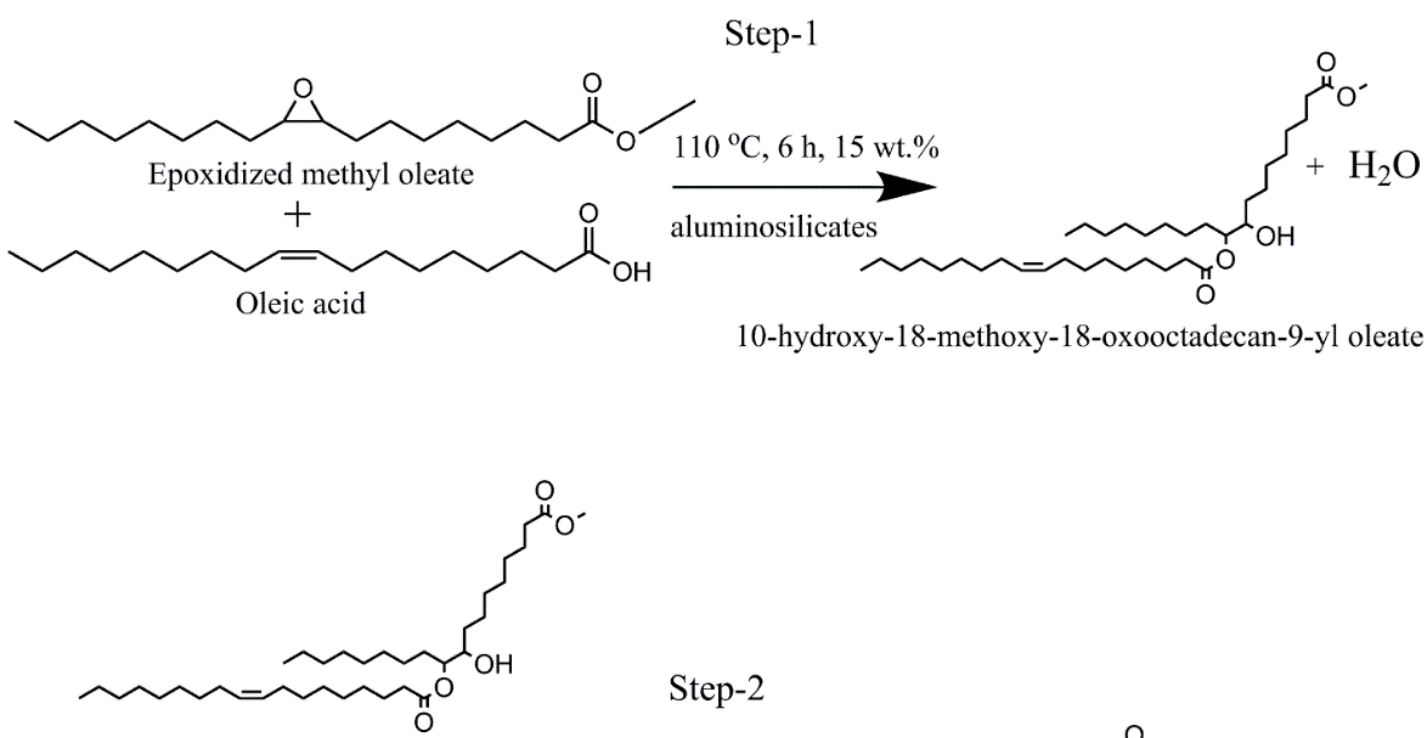

Step-2

10-hydroxy-18-methoxy-18-oxooctadecan-9-yl

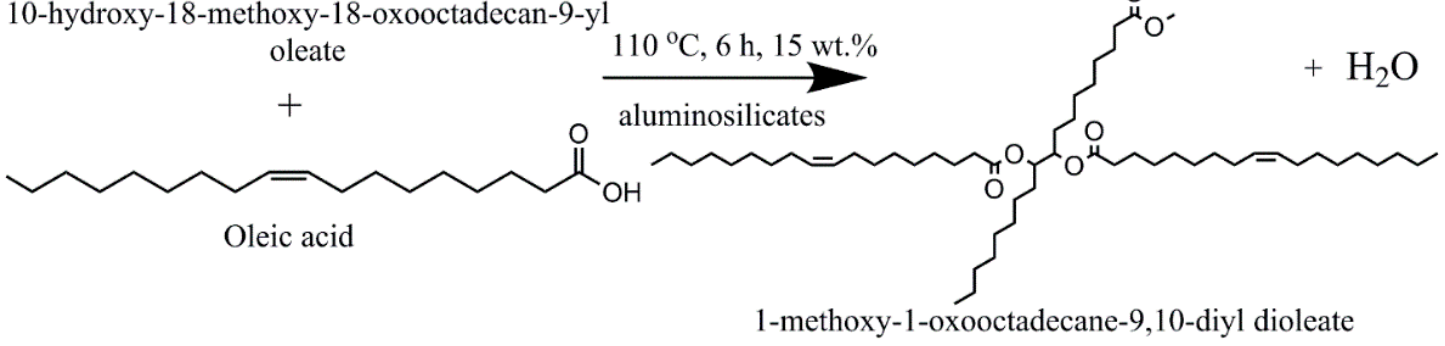

Scheme 1. Synthesis route for estolide formation from epoxidized oleic acid as model compound. 
Table 1. Selected process parameters chosen for the optimization of esterification.

\begin{tabular}{cc}
\hline Process Parameter & Range \\
\hline Oleic acid $(\mathrm{mol})$ & $6-12$ \\
Reaction time $(\mathrm{h})$ & $0-9$ \\
Reaction temperature $\left({ }^{\circ} \mathrm{C}\right)$ & $30-120$ \\
Catalyst loading $(\mathrm{wt} \%)$ & $5-20$ \\
\hline
\end{tabular}

\section{Results and Discussion}

\subsection{Catalyst Characterization}

An in-depth characterization was carried out for the catalyst to identify and measure the properties that are essential for the efficient catalysis towards the formulation of estolides. The $\mathrm{N}_{2}$-adsorption of aluminosilicates at $77 \mathrm{~K}$ shown type (IV) isotherm (Figure 1) with a hysteresis loop supporting their large pore size and mesoporous structure. The BET-specific surface area of the catalyst was found to be $1173 \mathrm{~m}^{2} / \mathrm{g}$ with a pore volume of $1.63 \mathrm{~cm}^{3} / \mathrm{g}$ and average mesopore pore diameter of $4.7 \mathrm{~nm}$. A mesoporous catalyst is favorable for large molecules like epoxidized canola biodiesel and is anticipated to increase the estolide formation via an oxirane ring opening followed by esterification. Earlier studies [11] disclosed that beyond the $\mathrm{Si} / \mathrm{Al}$ ratio of 32 in the prepared catalysts indicated the decrease in total pore volume; therefore, in the present study, $\mathrm{Si} / \mathrm{Al}$ ratio was maintained as 32. Presence of pentasil groups in the catalyst is indicated by the IR band (Figure 2) at $450 \mathrm{~cm}^{-1}$. Additional evidence for aluminosilicates, bands around 790, $1080 \mathrm{~cm}^{-1}$ are characteristic of $\mathrm{SiO}_{4}$ tetrahedron units. Transmission band around $1080 \mathrm{~cm}^{-1}$ is attributed to the internal asymmetric stretching vibration of $\mathrm{Si}-\mathrm{O}-\mathrm{Si}$ or $\mathrm{Si}-\mathrm{O}-\mathrm{Al}$ linkage. The absorption band by $450 \mathrm{~cm}^{-1}$ is attributed to the bending vibrations of tetrahedron-shaped orthosilicates and aluminates, which are in the form of the $\mathrm{SiO}_{4}$ and $\mathrm{AlO}_{4}$ internal tetrahedral. The presence of absorption bands around 450 and $540 \mathrm{~cm}^{-1}$ are characteristic of aluminosilicates [12-14].

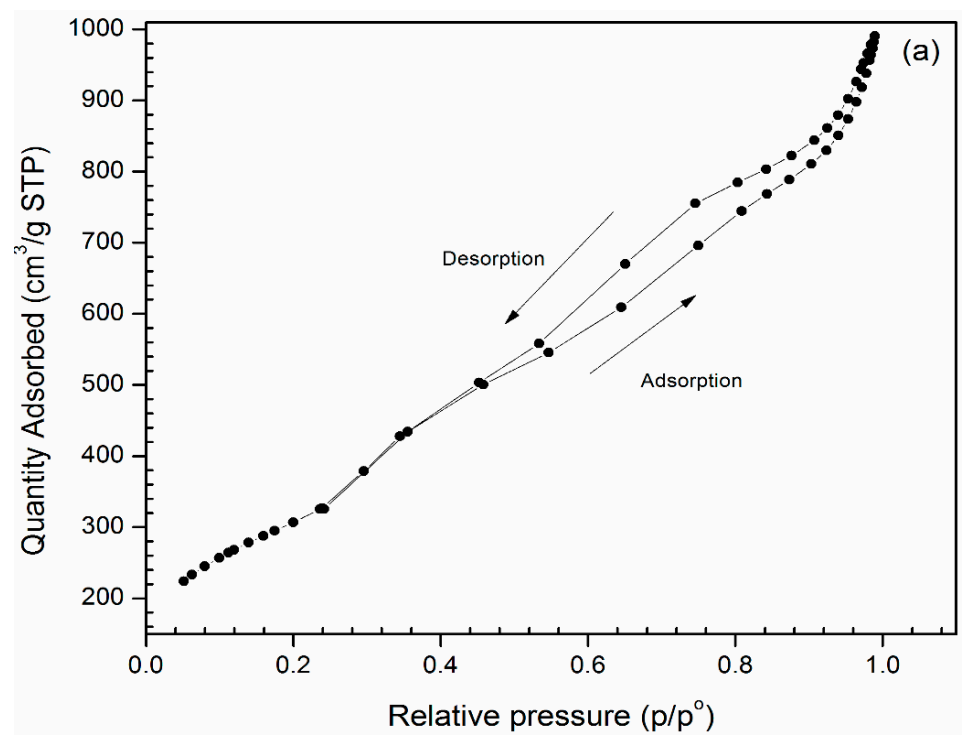

Figure 1. Cont. 


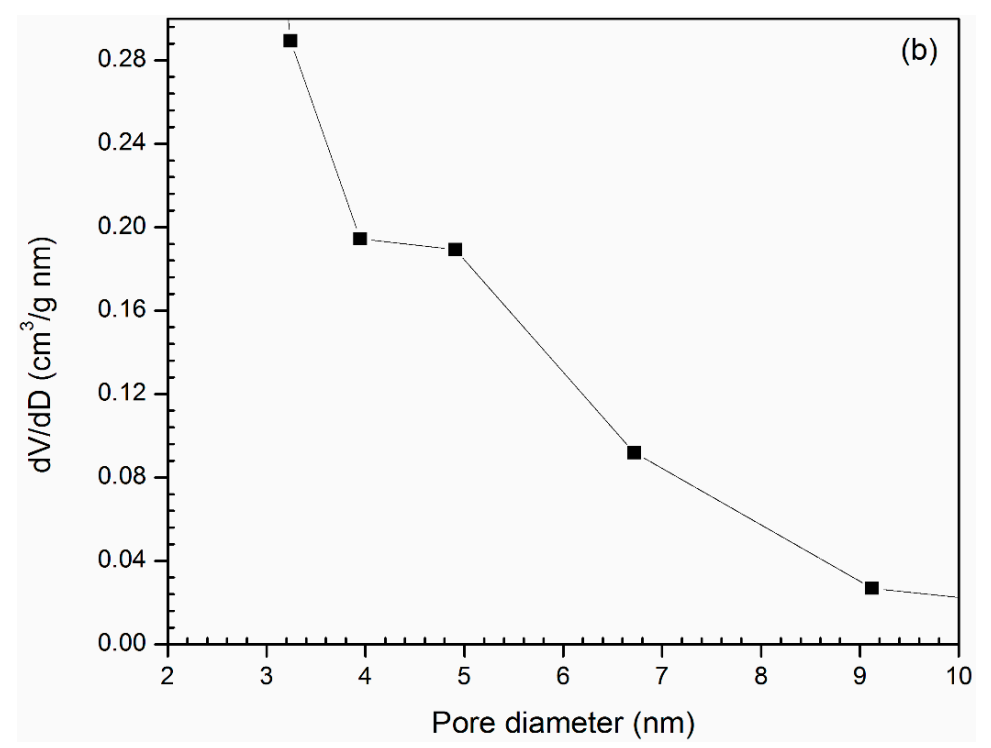

Figure 1. (a) $\mathrm{N}_{2}$ adsorption isotherm and (b) pore size distribution of the mesoporous aluminosilicates.

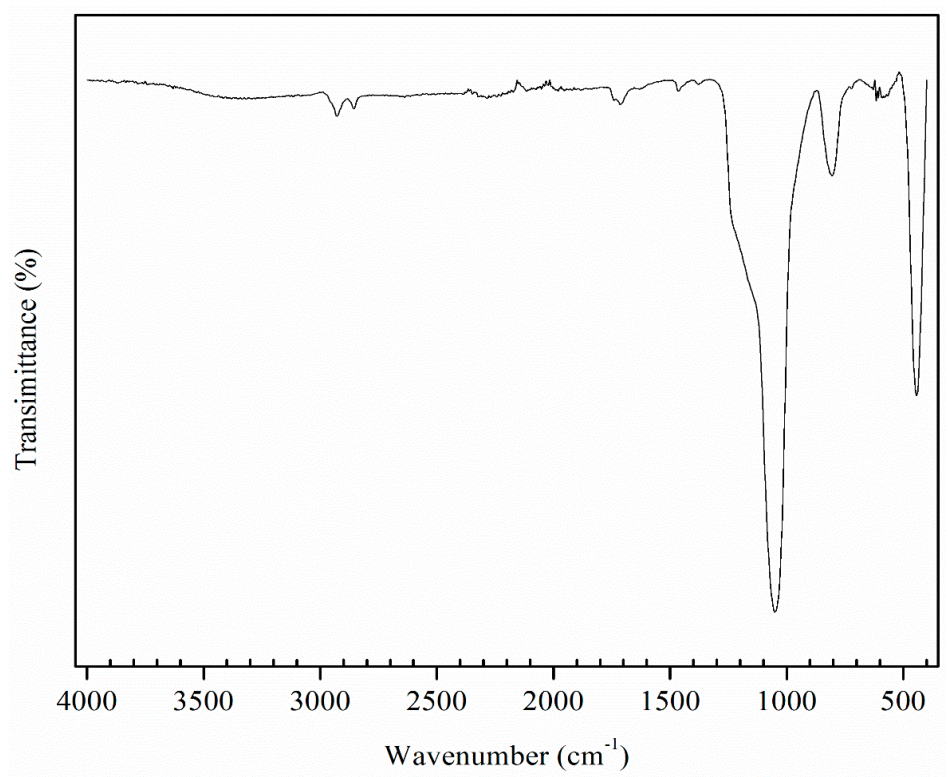

Figure 2. FTIR spectrum of the mesoporous aluminosilicates.

Figure 3 shows the $\mathrm{NH}_{3}$-TPD profile of aluminosilicates catalyst. From the figure, three ammonia desorption peaks were noticed between $80-600{ }^{\circ} \mathrm{C}$, indicating the presence of surface acidic sites. The desorption peak noticed between 100 and $280{ }^{\circ} \mathrm{C}$ (low intensity) relates to physisorption/chemisorption of ammonia on the weak acidic sites. The moderate and high-intensity desorption regions between the temperatures $300-440{ }^{\circ} \mathrm{C}$ and $440-560{ }^{\circ} \mathrm{C}$ are due to moderate and strong acidic sites, respectively (Table 2). The wider desorption peak in the lower intensity area indicates that the zeolite has a higher useful group of weak surface acidic sites $[11,15,16]$. The XRD pattern of the catalyst is presented in Figure S1. From the Figure, it can be seen that the catalyst produced amorphous peaks ( $2 \theta$ at $12.5^{\circ}$ and $28.9^{\circ}$ ), which correspond to the aluminosilicates (JCPDS No. 42-0023) [17]. Also, the characteristic peaks of the catalyst configuration designate higher crystalline structures and purity which are characterized to be zeolites. Low intensity of the peak with $2 \theta$ at $12.5^{\circ}$ attributed to the less crystallinity of the zeolites with high aluminum content. The relative crystallinity was calculated using the Scherer equation and it was found to be $26-29 \mathrm{~nm}$. 


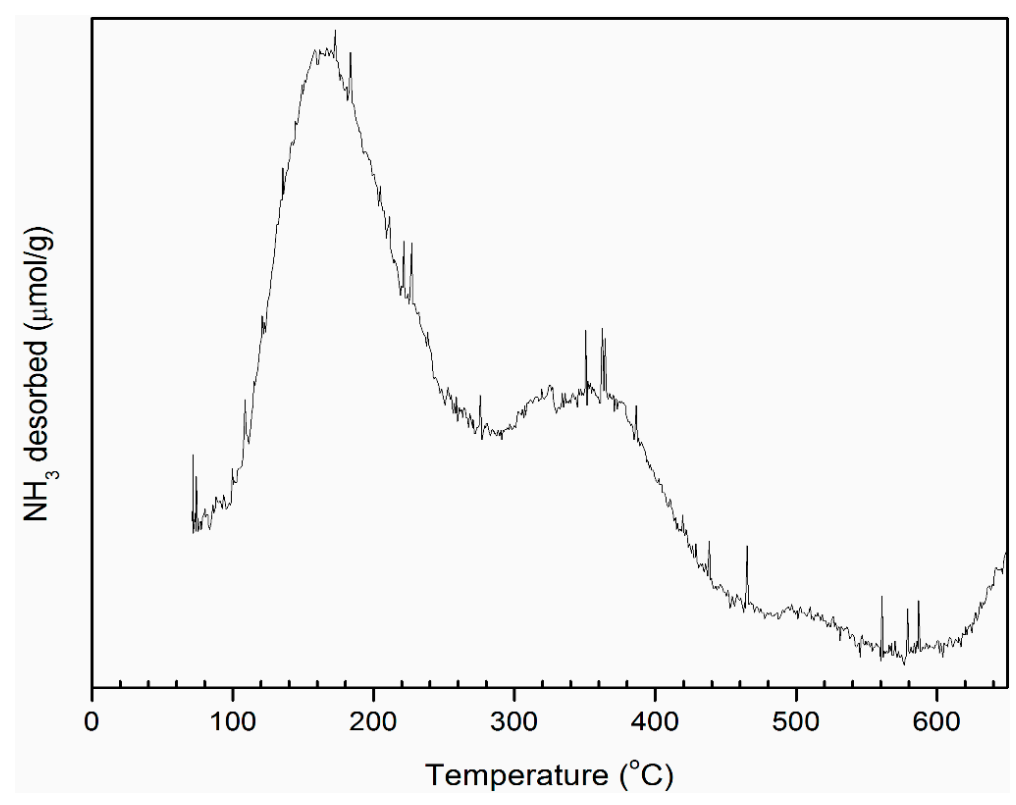

Figure 3. $\mathrm{NH}_{3}-\mathrm{TPD}$ profile of the mesoporous aluminosilicates.

Table 2. $\mathrm{NH}_{3}$-temperature programmed desorption of the mesoporous aluminosilicates at different temperatures.

\begin{tabular}{cccc}
\hline Name of the Catalyst & $\begin{array}{c}\text { Maximum Desorption } \\
\text { Temperature }\left({ }^{\circ} \mathbf{C}\right)\end{array}$ & $\begin{array}{c}\text { Amount of Ammonia } \\
(\mu \mathrm{L} / \mathbf{g} \text { cat })\end{array}$ & $\begin{array}{c}\text { Acid Strength } \\
\text { (mmol/g cat) }\end{array}$ \\
\hline \multirow{2}{*}{ Mesoporous } & 167 & 49.91 & 0.484 \\
aluminosilicates & 401 & 53.67 & 0.520 \\
& 548 & 2.25 & 0.021 \\
\hline
\end{tabular}

To confirm the expected compositions of the catalyst, significant peaks (O-1s, Si-2 $\left.\mathrm{p}_{3 / 2}, \mathrm{Al}-2 \mathrm{p}_{3 / 2}\right)$ relevant to this study are identified and shown in Figures S2-S4. Significantly, XPS analysis was carried out to find data on the relative intensities of the detected peaks, thus determining the chemical composition at the surface of the catalyst. Survey scan of the XPS spectra has shown the presence of $\mathrm{Si}, \mathrm{O}, \mathrm{C}$ and $\mathrm{Al}$ at binding energies between 99.36-106.28 eV, 536.24-527.19 eV, 281.01-291.59 eV and 98.74-107.03 eV respectively. In a detailed XPS investigation, it was found that aluminum species are present on the aluminosilicates surfaces, which is a similar finding from the Barr and Lishka [18]. The binding energy and fwhm (full width at half maxima) values for $\mathrm{O}(1 \mathrm{~s}), \mathrm{Si}\left(2 \mathrm{p}_{3 / 2}\right), \mathrm{Al}\left(2 \mathrm{p}_{3 / 2}\right)$, and $\mathrm{Al}$ (KLL) levels agree well with those of Vedrine et al. [19] and Ratnasamy et al. [20].

Figure 4 shows the differential thermal analysis and thermogravimetric (DTG/TGA) of the catalyst. Only $4 \%$ weight loss was observed and it was attributed to the desorption of water, which was strongly combined in the aluminosilicates and the disintegration of a carbon-based composite such as TPAOH and the transformation of hydroxide mixtures to oxide form [17]. 


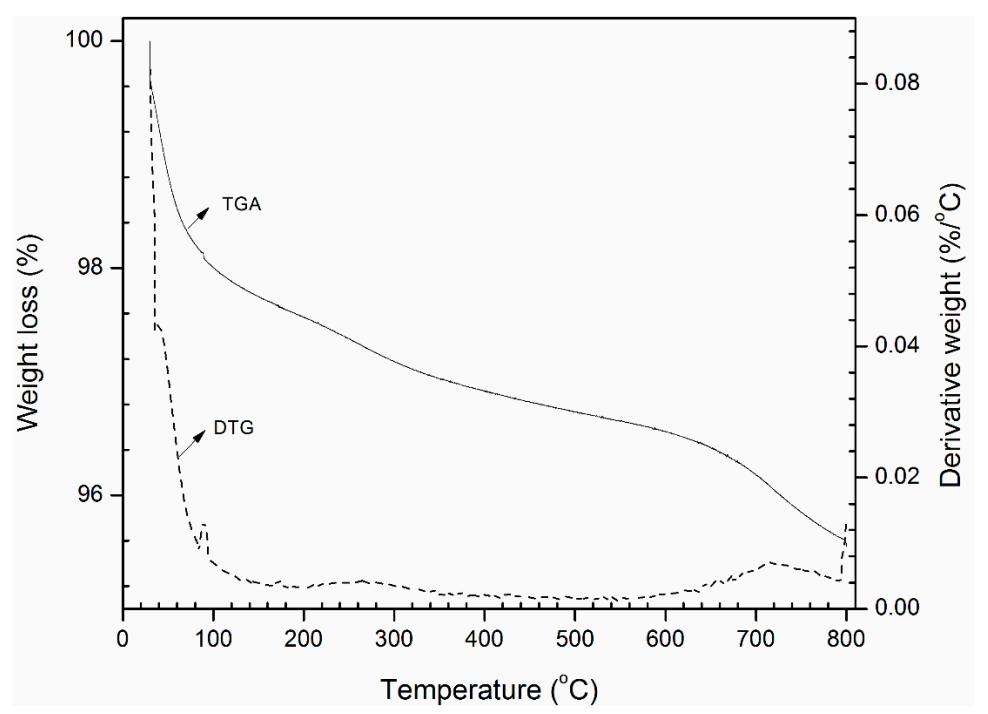

Figure 4. Thermogravimetric and differential thermal analysis of the mesoporous aluminosilicates.

\subsection{Product Confirmation and Characterization of Estolides by ${ }^{1} H-N M R$}

The ${ }^{1} \mathrm{H}$ NMR is one of the most reliable spectral techniques to monitor and identify the reaction products. The ${ }^{1} \mathrm{H}$ NMR spectra of epoxidized canola biodiesel (Figure 5a) and estolides are shown in Figure $5 \mathrm{a}, \mathrm{b}$. In Figure $5 \mathrm{a}$, the proton chemical shifts between $\delta 2.9$ to $\delta 3.2 \mathrm{ppm}$ is the characteristic of the epoxy protons, indicating the oxirane in epoxidized canola biodiesel. Likewise, the estolides spectrum (Figure 5b) shows the deficiency of epoxy protons at $\delta 2.9$ to $\delta 3.2 \mathrm{ppm}$ signifying that epoxy protons were consumed during the nucleophilic attack and esterification reactions during estolides formation. It can also be affirmed by the appearance of a mono-unsaturated oleic acid peak at $5.4 \mathrm{ppm}$ (Figure 5b). Among all the process conditions from Table 1, 1:10 molar ratio of epoxide to oleic acid, $15 \mathrm{wt} \%$ of catalyst loading, $6 \mathrm{~h}$ of reaction time, $110{ }^{\circ} \mathrm{C}$ of reaction temperature was found to be optimum. Initial oxirane oxygen content of the epoxidized canola biodiesel was found to be $5.8 \mathrm{mass} \%$ and estolides oxirane oxygen content was found to be 0.06 mass $\%$ ( $96 \%$ conversion) at this process condition.

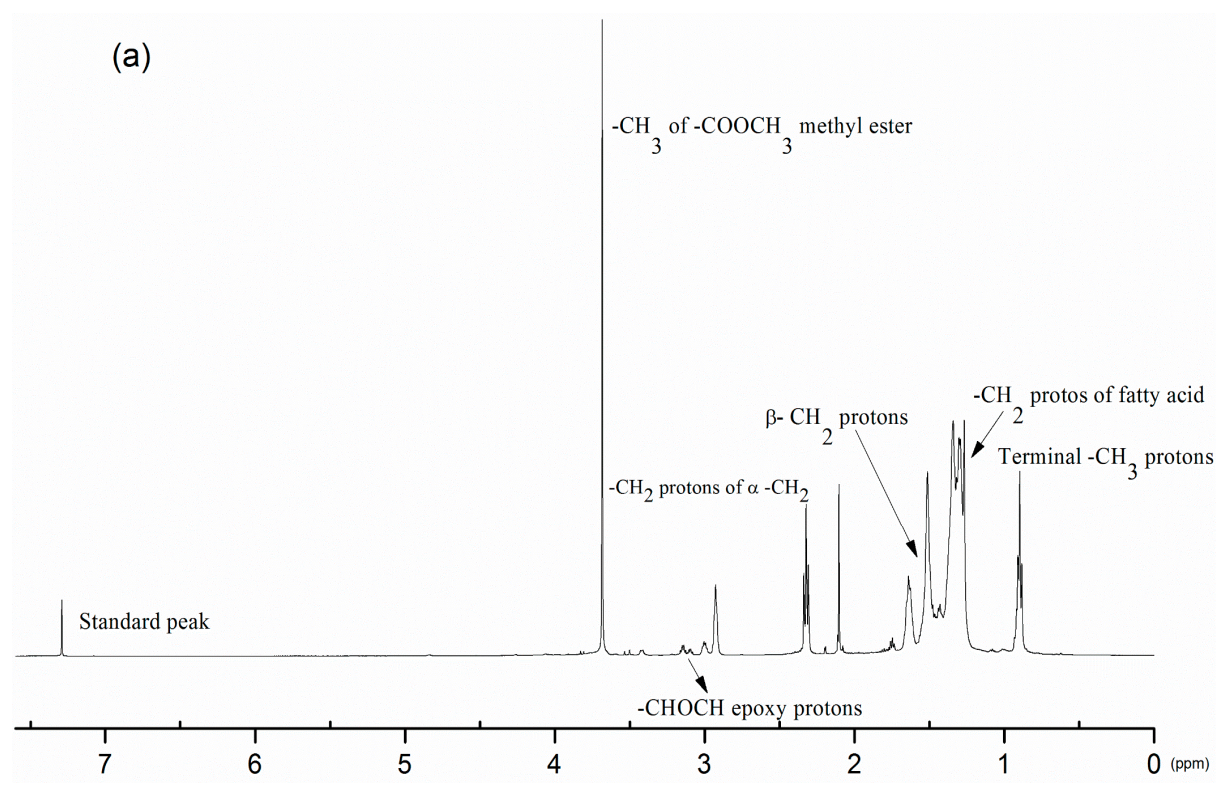

Figure 5. Cont. 


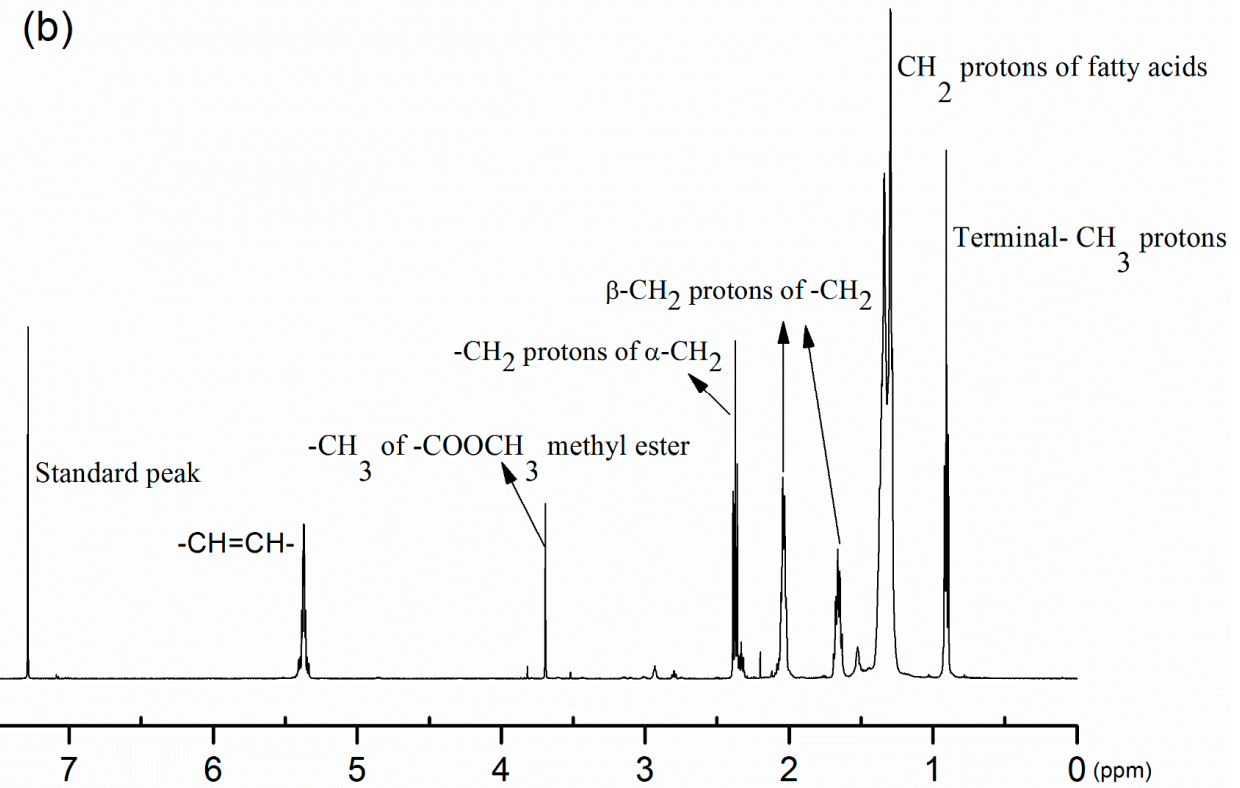

Figure 5. ${ }^{1} \mathrm{H}$ NMR spectra of (a) Epoxidized canola biodiesel and (b) Estolide.

The influence of the four process parameters such as reaction temperature, catalyst loading, epoxide to oleic acid molar ratio, and reaction time was studied via single parameter optimization experimental runs. Preliminary experimental runs conducted at lower temperature disclosed very slow rate of reaction and complete conversion was found to be challenging to achieve. Similarly, lower oleic acid molar ratios couldn't meet complete conversion, since oleic acid needs to be consumed in two series of reactions (ring opening and esterification). Lower catalyst loading was not sufficient to provide enough surface area for the reaction to take place, hence, the aforementioned process condition is considered as optimum. The complete epoxide conversion to estolides was evaluated by oxirane oxygen volumetric titration method (AOCS Cd 9-57) and supported with a ${ }^{1} \mathrm{H}$ NMR technique which is discussed above.

\subsection{Detailed Physicochemical Characterization of Formulated Estolides}

From the previous studies on estolide formulation, they were known for interesting chemical behavior, superior biodegradability, and better lubricity properties compared to conventional lubricants [21]. Hence, evaluating the physicochemical properties of the formulated estolides aids in finding the suitable area of applications as biolubricant basestocks. Cold flow properties of the epoxidized canola biodiesel and formulated estolides are found to be $0{ }^{\circ} \mathrm{C}$ [22] and $-28 \pm 2.3^{\circ} \mathrm{C}$ (Figure 6) respectively. The low-temperature properties of estolides are enhanced significantly $\left(-28^{\circ} \mathrm{C}\right)$ compared to epoxidized canola biodiesel $\left(0^{\circ} \mathrm{C}\right)$ due to the addition of oleic acid during oxirane ring opening followed by esterification. Upon functionalization of the oleic acid to epoxidized canola biodiesel, branching of the fatty acid structure was increased as shown in Scheme 1. In addition to the branching, the presence of the unsaturation in oleic acid promoted the resistance to the self-stacking of fatty acids present in the estolides at low temperatures and led to higher estolides mobility, up to $-28 \pm 2.3^{\circ} \mathrm{C}$ [23]. The pour points of the estolides are found to be promising and besides, they meet the standard lubricant specifications of ISO VG32, VG46, VG68, VG100 $\left(-6^{\circ} \mathrm{C}\right)$, SAE20W40 $\left(-21^{\circ} \mathrm{C}\right)$, and AG100 $\left(-18^{\circ} \mathrm{C}\right)$ [24]. During the study, it was determined that oleic acid branching at the center of the fatty acids (present in the epoxidized canola biodiesel) chain makes a stearic barrier around the different fatty acid molecules thereby crystallization was subdued, which results in the lower pour point of estolides. Similar explanations were also reported by other research investigations and lower pour-point estolides are suitable for engine oil and hydraulic oils $[10,25]$. 


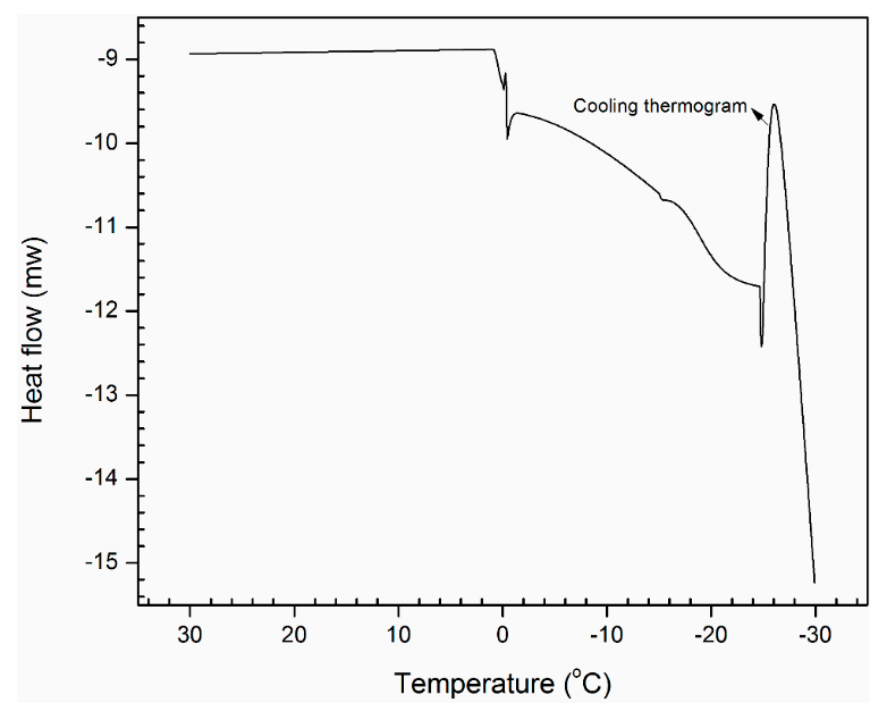

Figure 6. DSC cooling thermogram for estolides.

Rheological behavior of the estolides was estimated by shear rate versus shear stress curves at $40,60,80$, and $100{ }^{\circ} \mathrm{C}$ as shown in Figure 7a,b. The rheogram in Figure 7a shows a linear correlation between shear stress and shear rate, in spite of the temperature variations during the analysis. This behavior suggests a Newtonian flow behavior of the formulated estolides, and from the rheogram, it was also pointed out that the average shear stress decreased by increasing the shear rate and temperature. Similarly, Figure $7 \mathrm{~b}$ presents the shear rate versus viscosity measurement and despite the change in temperature, estolides showed a constant viscosity with a shear rate which further confirms Newtonian behavior. Further, evaluating the impact of temperature on viscosity of estolides shows an exponentially decreasing trend (Figure $7 \mathrm{~b}$ ), owing to the higher thermal moment among the fatty acid molecules.

Thus, based on the above rheological performance, it could be predicted that the estolides offer smooth functioning during their usage without any practical/operational problems. Further, the impact of the temperature on viscosity of epoxidized canola biodiesel and estolides were evaluated by determining their viscosity index and kinematic viscosity. The kinematic viscosity of the epoxidized canola biodiesel was found to be $14.91 \mathrm{cSt}$ at $40{ }^{\circ} \mathrm{C} ; 3.28 \mathrm{cSt}$ at $100{ }^{\circ} \mathrm{C}$ and viscosity index of 78.6. Similarly, kinematic viscosity of the estolides was found to be $11.3 \mathrm{cSt}$ at $40{ }^{\circ} \mathrm{C} ; 3.5 \mathrm{cSt}$ at $100{ }^{\circ} \mathrm{C}$ and viscosity index of 215. Comparative analysis of the viscosity and viscosity index of the epoxidized canola biodiesel and estolides showed that the viscosity of epoxidized canola biodiesel is $3.6 \mathrm{cSt}$ higher than that of estolides at $40^{\circ} \mathrm{C}$. Likewise, at $100{ }^{\circ} \mathrm{C}$ viscosity of epoxidized canola biodiesel and estolides was found to be identical, and estolides had 2.7 times higher viscosity index (215) than that of the epoxidized canola biodiesel (78.6). The viscosity index of formulated estolides in this study are higher than the standard lubricant requirements of ISO VG32 (>90), VG46 (>90), VG68 (>198), Paraffin VG95 (102), VG460 (97), SAE20W40 (132), AG100 (103), 75W-90 (140), 75W-140 (174), 80W-140 (139) [24].

The critical property of the lubricants is to maintain the static lubricating film at the metallic interaction zone; thus the stationary lubricating film can stop the wear of metallic surface. Earlier studies state that derivatives from plant seed oils are renowned for their excellent lubricity properties [10]. The lubricity properties of the estolides were evaluated in terms of wear scar diameter to know the ability of the prepared estolides in reducing friction between moving surfaces. Lubricity characteristics were determined by HFRR apparatus and an optical microscope was used to measure the wear scar measurement (Figure 8). Initial wear scar diameter of the standard diesel was $600 \mu \mathrm{m}$ (Figure 8a), then the estolide was blended with standard diesel with $2 \mathrm{vol} \%, 5 \mathrm{vol} \%$ and $10 \% / \mathrm{vol}$ and tested for lubricity. The wear scar diameter found was $425 \pm 12.6 \mu \mathrm{m}$ with $2 \%$ blend (Figure $8 \mathrm{~b}$ ), $260 \pm 9.3 \mu \mathrm{m}$ with $5 \%$ blend (Figure 8c) and $106 \pm 7.4 \mu \mathrm{m}$ with $10 \%$ blend (Figure $8 \mathrm{~d}$ ). As the estolide 
volume is increasing in the blend, reduction in the wear scar diameter is noticed, which confirms that estolides are rendering lubricity among moving surfaces, which resulted in a decline in wear scar diameter. Improved lubricity of the estolides were owing to the presence of the unsaturation present in the oleic acid, and the branching on the fatty acid chains enables the estolides to stick to the metallic surface, thereby an antifrictional film developed [25].
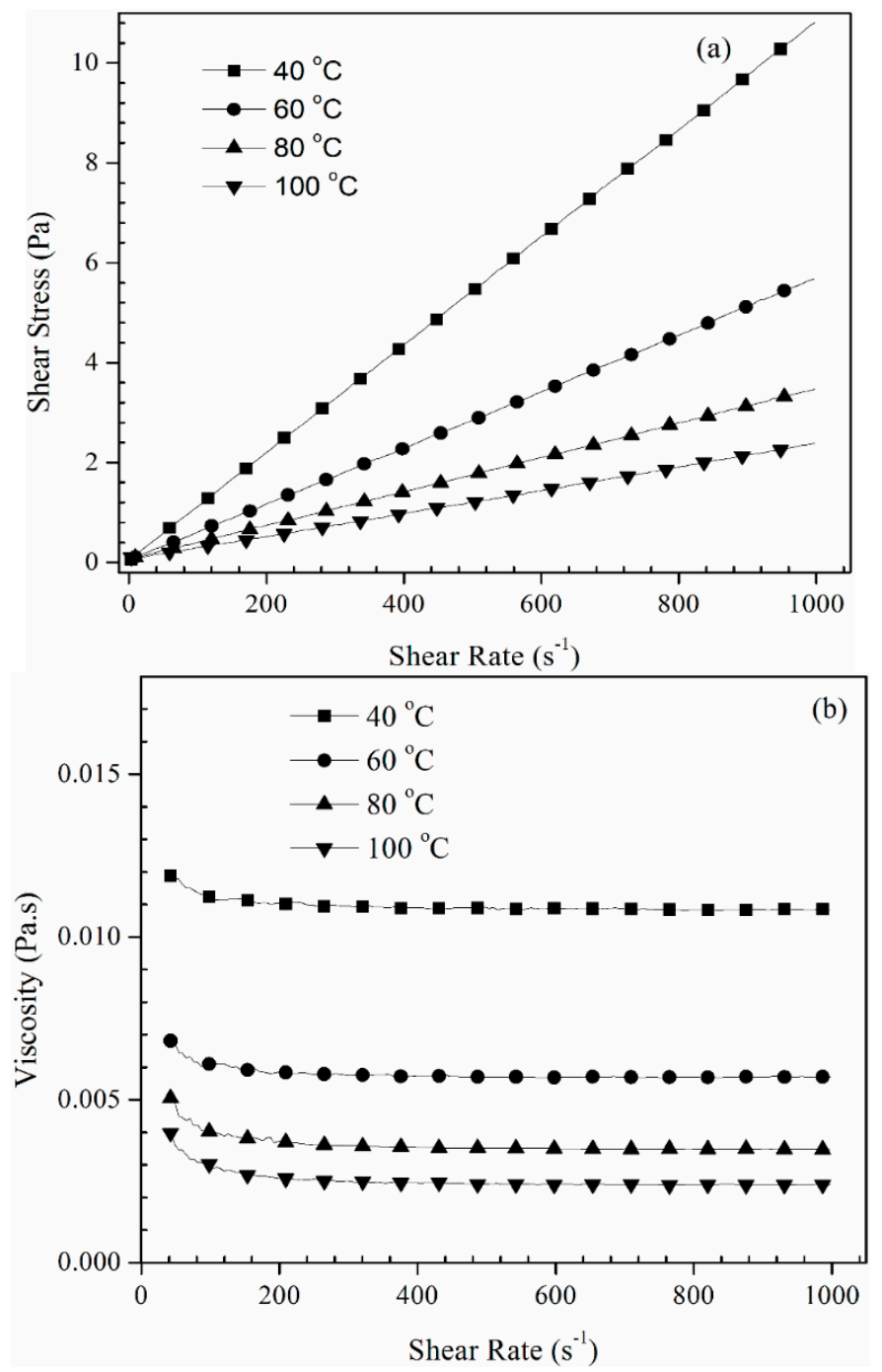

Figure 7. (a) Shear rate vs. shear stress and (b) shear rate vs. viscosity relationships for estolides.

The production and commercialization of the estolides become significant owing to the lower biodegradability of the crude oil derivatives. Biodegradability denotes the perseverance of prepared estolides in the ecosystem. Reported biodegradability studies were based on extent of the ultimate aerobic mineralization of the testing material to $\mathrm{CO}_{2}$ in water [26,27]. The ratio of the biological oxygen demand to theoretical demand (BOD/ThOD) and total inorganic carbon dioxide production to theoretical inorganic carbon dioxide production (TIC/ThIC) was considered to analyze the biodegradation profile. Through these tests, if the degradation exceeds $60 \%$ within 28 days, the test sample is considered as "readily biodegradable" [26]. In the current study, the biodegradability of the estolides was estimated by the bio-kinetic model to evaluate the effective composition of biodegradation based on the aromatic and ester fractions present in the estolides. The calculated biodegradation profile of identical experiments carried out for estolides was found to be $92 \pm 4.6 \%$. From the duplicate test runs, estolides are found to be easily biodegradable and showed good reproducibility. Due to the absence of glycerol moiety in the estolides, less biodegradability was 
noticed during this study, the presence of the glycerol promotes the bio-degradation at a faster rate. However, during this study prepared estolides are found to be easily biodegradable within 28 days, therefore they won't contribute any damage to the ecosystem, thus they could be considered as ecofriendly estolides.
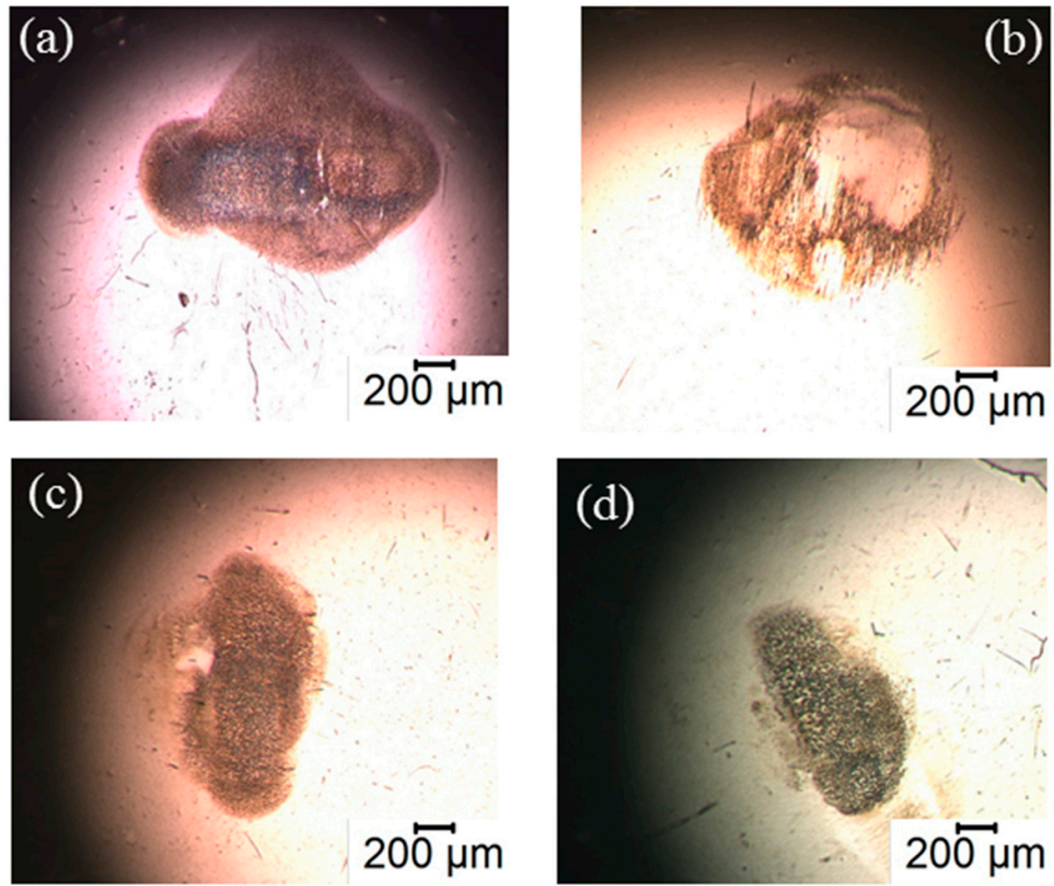

Figure 8. Images of the wear scars on the (a) standard diesel fuel; (b) $2 \%$; (c) $5 \%$; (d) $10 \%$ blends of alkoxides in standard diesel fuel.

\section{Conclusions}

The chemical modification of unsaturated fatty acids present in canola biodiesel to epoxides and estolides was performed with simple reagents via epoxidation, an oxirane ring opening followed by esterification. This synthesis route is a viable strategy for altering the functionality, physicochemical properties of the estolides, and aluminosilicates was found to be the promising catalyst for oxirane ring opening and esterification reactions due to the combination of strong acidity, small crystallites, and high external surface area. Formulation of the estolides was attributed to the presence of Si, Al, and weak and medium acidic sites on the catalyst. The in-situ synthesis was effective for the estolides formulation via the epoxidation route. The estolide products were confirmed by ${ }^{1} \mathrm{H}$ NMR and further supported by oxirane analysis. The optimum conditions for the in-situ synthesis of estolides from epoxidized canola biodiesel as follows: oleic acid to epoxide molar ratio (1:10), $110{ }^{\circ} \mathrm{C}$ reaction temperature, $6 \mathrm{~h}$ of reaction time, and $15 \mathrm{wt} \%$ of catalyst loading. Physicochemical characterization of the estolides showed significantly improved low-temperature properties $\left(-28{ }^{\circ} \mathrm{C}\right)$ and biodegradability $(92 \%)$ than that of epoxidized canola biodiesel, including a reduced wear-scar diameter $(106 \mu \mathrm{m})$ for a $10 \%$ blend. Therefore, the results of this study have shown that these estolides could be a possible complement to the ISO VG32, VG46, VG68, Paraffin VG95, VG460, SAE20W40, AG100, 75W-90, 75W-140, and 80W-140 standard lubricants.

Supplementary Materials: The following are available online at http:/ / www.mdpi.com/2075-4442/6/4/94/s1. S1. Cermak and Isabell's contributions on formulation of estolides, Figure S1: XRD spectra of the mesoporous aluminosilicates catalyst, Figure S2: XPS spectra of $\mathrm{O}(1 \mathrm{~s})$ for $\mathrm{SiO}_{2}$ in mesoporous aluminosilicates, Figure S3: XPS spectra of $\mathrm{Si}(2 \mathrm{p})$ for $\mathrm{SiO}_{2}$ in mesoporous aluminosilicates, Figure S4: XPS spectra of $\mathrm{Al}(2 \mathrm{p})$ for $\mathrm{Al}_{2} \mathrm{O}_{3}$ in mesoporous aluminosilicates, Supplementary References. 
Author Contributions: Conceptualization, V.B.B.; Formal Analysis, V.B.B.; Methodology, V.B.B.; Supervision, A.K.D.; Writing-Original Draft, V.B.B.; Writing-Review \& Editing, A.K.D.

Funding: This research received no external funding.

Conflicts of Interest: The authors declare no conflict of interest.

\section{References}

1. Yunus, R.; Luo, X. Thermochemical conversion of plant oils and derivatives to lubricants. Adv. Bioenergy 2017, 2, 183-231.

2. Borugadda, V.B.; Goud, V.V. Improved low-temperature properties of chemically modified high free fatty acid castor oil-methyl esters: Blending and optimization study. J. Energy Eng. 2015. [CrossRef]

3. Borugadda, V.B.; Goud, V.V. Comparative studies of thermal, oxidative and low-temperature properties of waste cooking oil and castor oil. J. Renew. Sustain. Energy 2013, 5. [CrossRef]

4. Cermak, S.C.; Isbell, T.A. Improved oxidative stability of estolide esters. Ind Crops Prod. 2003, 18, $223-230$. [CrossRef]

5. Cermak, S.C.; Isbell, T.A. Physical properties of saturated estolides and their 2-Ethylhexyl esters. Ind. Crops Prod. 2002, 16, 119-127. [CrossRef]

6. Kiatsimkul, P.P.; Suppes, G.J.; Hsieh, F.H.; Lozada, Z.; Tu, Y.C. Preparation of high hydroxyl equivalent weight polyols from vegetable oils. Ind. Crops Prod. 2008, 27, 257-264. [CrossRef]

7. Ashby, R.D.; Solaiman, D.K.Y.; Liu, C.K.; Strahan, G.; Latona, N. Sophorolipid-derived unsaturated and epoxy fatty acid estolides as plasticizers for poly (3-Hydroxybutyrate). J. Am. Oil Chem. Soc. 2016, 93, 347-358. [CrossRef]

8. Doll, K.M.; Cermak, S.C.; Kenar, J.A.; Isbell, T.A. Synthesis and characterization of estolide esters containing epoxy and cyclic carbonate groups. J. Am. Oil Chem. Soc. 2016, 93, 1149-1155. [CrossRef]

9. Doll, K.M.; Cermak, S.C.; Kenar, J.A.; Walter, E.L.; Isbell, T.A. Derivatization of castor oil based estolide esters: Preparation of epoxides and cyclic carbonates. Ind. Crops Prod. 2017, 104, 269-277. [CrossRef]

10. Borugadda, V.B.; Somidi, A.K.R.; Dalai, A.K. Chemical/structural modification of canola oil and canola biodiesel: Kinetic studies and biodegradability of the alkoxides. Lubricants 2017, 5, 1-14. [CrossRef]

11. Bai, P.; Wu, P.; Xing, W.; Liu, D.; Zhao, L.; Wang, Y.; Xu, B.; Yan, Z.; Zhao, X.S. Synthesis and catalytic properties of ZSM- 5 zeolite with hierarchical pores prepared in the presence of $n$-hexyltrimethylammonium bromide. J. Mater. Chem. 2015, 3, 18586-18597. [CrossRef]

12. Feng, H.; Li, C.; Shan, H. In-situ synthesis and catalytic activity of ZSM-5 zeolite. App. Clay Sci. 2009, 42, 439-445. [CrossRef]

13. Barot, S.; Bandyopadhyay, R.; Joshi, S.S. Catalytic conversion of jatropha oil to biofuel over titania, zirconia and ceria loaded amorphous alumino-silicate catalysts. Environ. Progres. Sustain. Energy 2017, 36, 749-757. [CrossRef]

14. Kirschhock, C.E.A.; Ravishankar, R.; Verspeurt, F.; Grobet, P.J.; Jacobs, P.A.; Martens, J.A. Identification of precursor spices in the formation of MFI zeolite in the TPAOH-TEOS- $\mathrm{H}_{2} \mathrm{O}$ system. J. Phys. Chem. B 1999, 111, 4965-4971. [CrossRef]

15. Choi, M.; Cho, H.S.; Srivastava, R.; Venkatesan, C.; Choi, D.H.; Ryoo, R. Amphiphilic organosilane-directed synthesis of crystalline zeolite with tunable mesoporosity. Nat. Mater. 2006, 5, 718-723. [CrossRef] [PubMed]

16. Choi, M.; Na, K.; Kim, J.; Sakamoto, Y.; Terasaki, O.; Ryoo, R. Stable single-unit-cell nanosheets of zeolite MFI as active and long-lived catalysts. Nature 2009, 461, 246-249. [CrossRef] [PubMed]

17. Hassanpour, S.; Taghizadeh, M. Preparation, characterization, and activity evaluation of H-ZSM-5 catalysts in vapor-phase methanol dehydration to dimethyl ether. Ind. Eng. Chem. Res. 2010, 49, 4063-4069. [CrossRef]

18. Barr, T.L.; Lishka, M.A. ESCA studies of the surface chemistry of zeolites. J. Am. Chem. Soc. 1986, 108, 3178. [CrossRef]

19. Auroux, A.; Bolis, V.; Wierzchowski, P.; Gravelle, P.C.; Vedrine, J.C. Study of the acidity of ZSM-5 zeolite by microcalorimetry and infrared spectroscopy. J. Chem. Soc. 1979, 59, 2544-2555. [CrossRef]

20. Badrinarayana, S.; Hegde, R.I.; Balakrishnan, L.; Kulkarni, S.B.; Ratnasamy, P. XPS study of nickel in NiHZSM5 catalysts. J. Catal. 1981, 71, 439-442. [CrossRef]

21. Cermak, S.C.; Isbell, T.A. Synthesis of estolides from oleic and saturated fatty acids. J. Am. Chem. Soc. 2001, 78, 557-565. [CrossRef] 
22. Sharma, R.V.; Somidi, A.K.R.; Dalai, A.K. Preparation and property evaluation of biolubricants derived from canola oil and canola biodiesel. J. Agric. Food Chem. 2015, 63, 3235-3242. [CrossRef] [PubMed]

23. Borugadda, V.B.; Goud, V.V. Synthesis of waste cooking oil epoxide as a bio-lubricant base stock: characterization and optimization study. J. Bioprocess Eng. Biorefin. 2014, 3, 57-72. [CrossRef]

24. McNutt, J.; He, Q.S. Development of biolubricants from vegetable oils via chemical modification. J. Ind. Eng. Chem. 2016, 36, 1-12. [CrossRef]

25. Adhvaryu, A.; Erhan, S.Z.; Perez, J.M. Tribological studies of thermally and chemically modified vegetable oils for use as environmentally friendly lubricants. Wear 2004, 257, 359-367. [CrossRef]

26. Strotman, U.; Reuschenbach, P.; Schwarz, H.; Pagga, U. Development and evaluation of an online $\mathrm{CO}_{2}$ evolution test and multicomponent biodegradation test system. Appl. Environ. Microbiol. 2004, 70, 4621-4628. [CrossRef] [PubMed]

27. Pakou, C.; Stamatelatou, K.; Kornaros, M.; Lyberatos, G. On the complete aerobic microbial mineralization of linear alkylbenzene sulfonate. Desalination 2007, 215, 198-208. [CrossRef]

(C) 2018 by the authors. Licensee MDPI, Basel, Switzerland. This article is an open access article distributed under the terms and conditions of the Creative Commons Attribution (CC BY) license (http:// creativecommons.org/licenses/by/4.0/). 